\title{
Activation of PPARy/P53 signaling is required for curcumin to induce hepatic stellate cell senescence
}

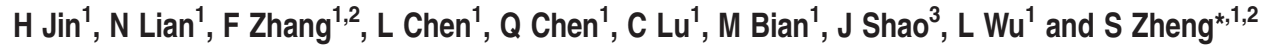

Activation of quiescent hepatic stellate cells (HSCs) is the major event in hepatic fibrogenesis, along with enhancement of cell proliferation and overproduction of extracellular matrix. Although inhibition of cell proliferation and induction of apoptosis are potential strategies to block the activation of HSCs, a better understanding of the senescence of activated HSCs can provide a new therapeutic strategy for prevention and treatment of liver fibrosis. The antioxidant curcumin, a phytochemical from turmeric, has been shown to suppress HSC activation in vitro and in vivo. The current work was aimed to evaluate the effect of curcumin on senescence of activated HSCs and to elucidate the underlying mechanisms. In this study, curcumin promoted the expression of senescence marker Hmga1 in rat fibrotic liver. In addition, curcumin increased the number of senescence-associated $\beta$-galactosidase-positive HSCs in vitro. At the same time, curcumin induced HSC senescence by elevating the expression of senescence markers P16, P21 and Hmga1, concomitant with reduced abundance of HSC activation markers $\alpha$-smooth muscle actin and $\alpha 1(\mathrm{I})$-procollagen in cultured HSCs. Moreover, curcumin affected the cell cycle and telomerase activity. We further demonstrated that P53 pharmacological inhibitor pifithrin- $\alpha$ (PFT- $\alpha$ ) or transfection with P53 siRNA abrogated the curcumininduced HSC senescence in vitro. Meanwhile, curcumin disruption of P53 leading to increased senescence of activated HSCs was further verified in vivo. Further studies indicated that curcumin promoted the expression of P53 through a PPAR $\gamma$ activationdependent mechanism. Moreover, promoting PPAR $\gamma$ transactivating activity by a PPAR $\gamma$ agonist 15d-PGJ2 markedly enhanced curcumin induction of senescence of activated HSCs. However, the PPAR $\gamma$ antagonist PD68235 eliminated curcumin induction of HSC senescence. Taken together, our results provided a novel insight into the mechanisms underlying curcumin inhibition of HSC activation through inducing senescence.

Cell Death and Disease (2016) 7, e2189; doi:10.1038/cddis.2016.92; published online 14 April 2016

Hepatic stellate cells (HSCs), previously known as vitamin A-storing cells or Ito cells, are the major effector cells in the development of liver fibrosis. ${ }^{1,2}$ Upon the liver injury, quiescent HSCs become activated and trans-differentiate into myofibroblast-like cells, which are characterized by enhanced cell growth and undergo profound phenotypic changes, including de novo expression of a-smooth muscle actin ( $a$-SMA) and production of large amounts of collagens. ${ }^{3,4}$ It has been recognized that suppression of the activation of HSCs can prevent and treat hepatic fibrosis. Typically, inhibition of cell proliferation and induction of apoptosis are potential strategies to block the activation of HSCs, but induction of activated HSC senescence could be a new therapeutic strategy for prevention and treatment of liver fibrosis. Recent evidence has revealed that the senescence of activated HSCs was an important step in limiting the fibrogenic response to liver tissue damage. 5,6

Cellular senescence is described as an antiproliferative program that leads to permanent growth arrest in the cell. ${ }^{7}$ Cellular senescence is typically characterized by telomere shortening or telomere dysfunction, ${ }^{8,9}$ activation of genes at the INK4a/ARF locus ${ }^{10}$ and accumulation of DNA damage..$^{7,11}$ Senescent cells undergo a stable growth arrest mediated by interplay of multiple pathways. Recently, accumulating evidence has shown that the tumor suppressor P53 can regulate cellular senescence. ${ }^{12}$ The P53 can lead to cell cycle arrest, DNA repair and apoptosis predominantly when it becomes transcriptionally active in response to DNA damage, oncogene activation and hypoxia. ${ }^{13}$ Deletion of P53 is found to reduce HSC senescence leading to extensive liver fibrosis. ${ }^{5}$ Moreover, peroxisome proliferator activated receptor $\gamma$ (PPARy), one of the PPAR isoforms, is highly expressed in quiescent HSCs in the normal liver, but its expression and activity are dramatically diminished during HSC activation in vitro and in vivo. ${ }^{14,15} \mathrm{~A}$ recent study has found that PPARy could play a potential role in liver fibrosis, which could regulate HSC senescence. ${ }^{16}$

The polyphenolic antioxidant curcumin, a primary active component of the rhizome of the plant turmeric (Curcuma longa Linn), possesses antiproliferative, antioxidant, anti-inflammatory,

\footnotetext{
${ }^{1}$ Department of Pharmacology, School of Pharmacy, Nanjing University of Chinese Medicine, Nanjing 210023, China; ${ }^{2}$ Jiangsu Key Laboratory for Pharmacology and Safety Evaluation of Chinese Materia Medica, Nanjing University of Chinese Medicine, Nanjing 210023, China and ${ }^{3}$ Department of Pharmacy, School of Pharmacy, Nanjing University of Chinese Medicine, Nanjing 210023, China

*Corresponding author: S Zheng, Department of Pharmacology, School of Pharmacy, Nanjing University of Chinese Medicine, 138 Xianlin Avenue, Nanjing 210023 , Jiangsu, China. Tel: +86 25 86798154; Fax: +86 25 86798188; E-mail: nytws@ 163.com

Abbreviations: $\alpha$-SMA, $\alpha$-smooth muscle actin; CDKs, cyclin-dependent kinases; DMEM, Dulbecco's modified Eagle's medium; DMSO, dimethylsulfoxide; ECM, extracellular matrix; FBS, fetal bovine serum; GAPDH, glyceraldehyde phosphate dehydrogenase; HSCs, hepatic stellate cells; PBS, phosphate-buffered saline; PFT- $\alpha$, pifithrin- $\alpha$; PPAR $\gamma$, peroxisome proliferator activated receptor $\gamma$; SA- $\beta$-Gal, senescence-associated $\beta$-galactosidase

Received 16.1.16; revised 06.3.16; accepted 14.3.16; Edited by G Amarante-Mendes
} 
antiangiogenic and antitumor effects. Previous reports demonstrated that curcumin inhibited activation of HSC in vitro by suppressing cell growth and inhibiting production of extracellular matrix (ECM) components. ${ }^{17}$ Curcumin promoted the expression of PPARy and stimulated the activation of PPAR $y$, which was a precondition for curcumin to inhibit HSC activation. ${ }^{18}$ The purpose of the present study was to investigate the signal transduction pathways involved in curcumin induction of activated HSC senescence. We hypothesized that modulation of PPARy could contribute to curcumin induction of HSC senescence through promoting the expression of P53. We therefore performed in vivo and in vitro experiments to test the hypothesis.

\section{Results}

Curcumin promoted HSC senescence and P53 expression in rat fibrotic liver. Our previous data have sufficiently demonstrated that curcumin protected the liver from histological injury, pathological angiogenesis and fibrogenesis induced by chronic $\mathrm{CCl}_{4}$ injection in rats. ${ }^{19-21}$ In the present study, we examined the senescence marker in rat fibrotic liver firstly. Results from immunofluorescence staining showed that curcumin increased the expression of senescence marker Hmga1 ${ }^{22}$ in HSCs concomitant with the expression of $a$-SMA, the marker of HSC activation (Figure 1). To test the role of P53 in curcumin induction of HSC senescence in vivo, we examined the levels of P53 in rat fibrotic liver. Chronic $\mathrm{CCl}_{4}$ intoxication reduced the production of $\mathrm{P} 53$ in rat fibrotic liver, but curcumin significantly increased the expression of P53 in liver tissues (Figure 1).

\section{Curcumin promoted activated HSC senescence in vitro. We used cultured HSCs to test whether curcumin had direct effects on HSC activation and senescence. Etoposide is a recognized DNA-damaging agent, which can promote cellular senescence, and thus here Etoposide treatment served as a positive control. We investigated the effects of curcumin on cell proliferation and apoptosis in cultured HSCs initially. Cell Counting Kit-8 analysis indicated that the ability of cell proliferation was inhibited by treatment with curcumin (Figure 2a). TUNEL staining revealed that curcumin had effects on HSC apoptosis (Figure 2b). Next, we found that curcumin treatment increased the number of senescence-associated $\beta$-galactosidase $\left(\mathrm{SA}-\beta-\mathrm{Gal}^{+}\right)$-positive HSCs (Figure 2c). Meanwhile, curcumin exposure decreased the mRNA and protein levels of $a$-SMA and $a 1$ (I)-procollagen in cultured HSCs (Figures $2 \mathrm{~d}$ and $e$ ), suggesting that curcumin inhibited HSC activation. Our further results showed that curcumin promoted activated HSC senescence. Real-time PCR, western blot and immunofluorescence}

analyses of senescence-associated genes consistently showed that curcumin treatment upregulated the expression of senescence markers P16, P21 ${ }^{23}$ and Hmga1 (Figures 2d-f). Additional experiments were performed to verify the role of telomerase activity in curcumin induction of activated HSC senescence. We found that the telomerase activity was decreased in activated HSCs by curcumin (Figure 2g).

A well-known feature of cellular senescence is cell cycle arrest, which largely accounts for the growth inhibition in senescent cells. ${ }^{24} \mathrm{Next}$, we examined the cell cycle distribution by a flow cytometer. As shown in Figure $2 \mathrm{~h}, \mathrm{HSC}$ s treated with curcumin showed significantly higher proportions of G1 cells and lower proportions of $S$ cells compared with untreated HSCs. Cell cycle is influenced by multiple cyclins and cyclin-dependent kinases (CDKs). The cyclin D1/CDK4 complex together with the cyclin E1/CDK6 complex promote the G0- to S-phase transition. Western blot analyses indicated that curcumin downregulated the four molecules (Figure 2i). These data revealed that curcumin arrested HSCs at the G0/G1 checkpoint by inducing HSC senescence in activated HSCs.

Curcumin induced activated HSC senescence via a P53-dependent mechanism. P53 is the major mediator of cell cycle arrest and senescence in response to a series of cellular damage. ${ }^{25}$ As illustrated in Figures $3 a$ and $b$, the expression of P53 was dose- and time-dependently increased by curcumin. On the other hand, P53 inhibitor PFT- $\alpha$ decreased the number of SA- $\beta-\mathrm{Gal}^{+} \mathrm{HSCs}$, compared with the cells treated with curcumin alone (Figure $3 c$ ). At the same time, analyses of real-time PCR, western blot and immunofluorescence staining displayed that the P53 inhibitor PFT- $a$ enhanced the pro-fibrotic effects and weakened the pro-senescence effects of curcumin (Figures $3 d$, f and h). In addition, we tested the role of P53 with a different strategy that downregulated the P53 levels by siRNA silencing, and the results with P53 siRNA transfection were consistent with the experiments from treatment with PFT- $a$ (Figures $3 e$ and g). Taken together, these findings consistently revealed that curcumin promoted the senescence of activated HSCs by inducing the expression of P53.

P53 mediated curcumin-induced activated HSC senescence in vivo. Next, we examined whether disruption of P53 could affect the senescence of activated HSCs in vivo. Mice were divided into five groups and four of these groups were administrated with Ad.Fc, curcumin plus Ad.Fc, curcumin plus Ad.shP53 or Ad.shP53, respectively, throughout the 8-week period of $\mathrm{CCl}_{4}$ treatment. Liver fibrosis was demonstrated by histological analyses. Hematoxylin and eosin

Figure 1 Curcumin promoted HSC senescence and P53 expression in rat fibrotic liver. Rats were grouped as follows: group 1, vehicle control (no $\mathrm{CCl}_{4}$, no treatment); group 2, model group (with $\mathrm{CCl}_{4}$, no treatment); group 3, colchicine-treated group $\left(0.1 \mathrm{mg} / \mathrm{kg}+\mathrm{CCl}_{4}\right)$; group 4, curcumin-treated group $\left(100 \mathrm{mg} / \mathrm{kg}+\mathrm{CCl}_{4}\right)$; group 5 , curcumin-treated group $\left(200 \mathrm{mg} / \mathrm{kg}+\mathrm{CCl}_{4}\right)$; and group 6, curcumin-treated group $\left(300 \mathrm{mg} / \mathrm{kg}+\mathrm{CCl}_{4}\right)$. Liver sections were stained with immunofluorescence using antibodies against Hmga1 and P53. Antibody against $\alpha$-SMA was used to specifically stain HSCs, and DAPI to stain the nucleus. Bar graphs showed the percentage quantitation of fluorescent images of Hmga1 or P53-positive cells in total activated HSCs ( $\alpha$-SMA as a marker) using the software Image $J$ as shown in the figure. ${ }^{* \star} P<0.001$ versus group 2. Scale bar, $50 \mu \mathrm{m}$ 
(H\&E), Masson and picro-Sirius red staining showed that the inhibitory effect of curcumin on liver fibrogenesis was remarkably decreased by interrupting P53 in the model
(Figure 4a). Moreover, livers derived from mice treated with curcumin plus Ad.shP53 exhibited downregulated levels of the senescence marker P16, compared with the mice treated

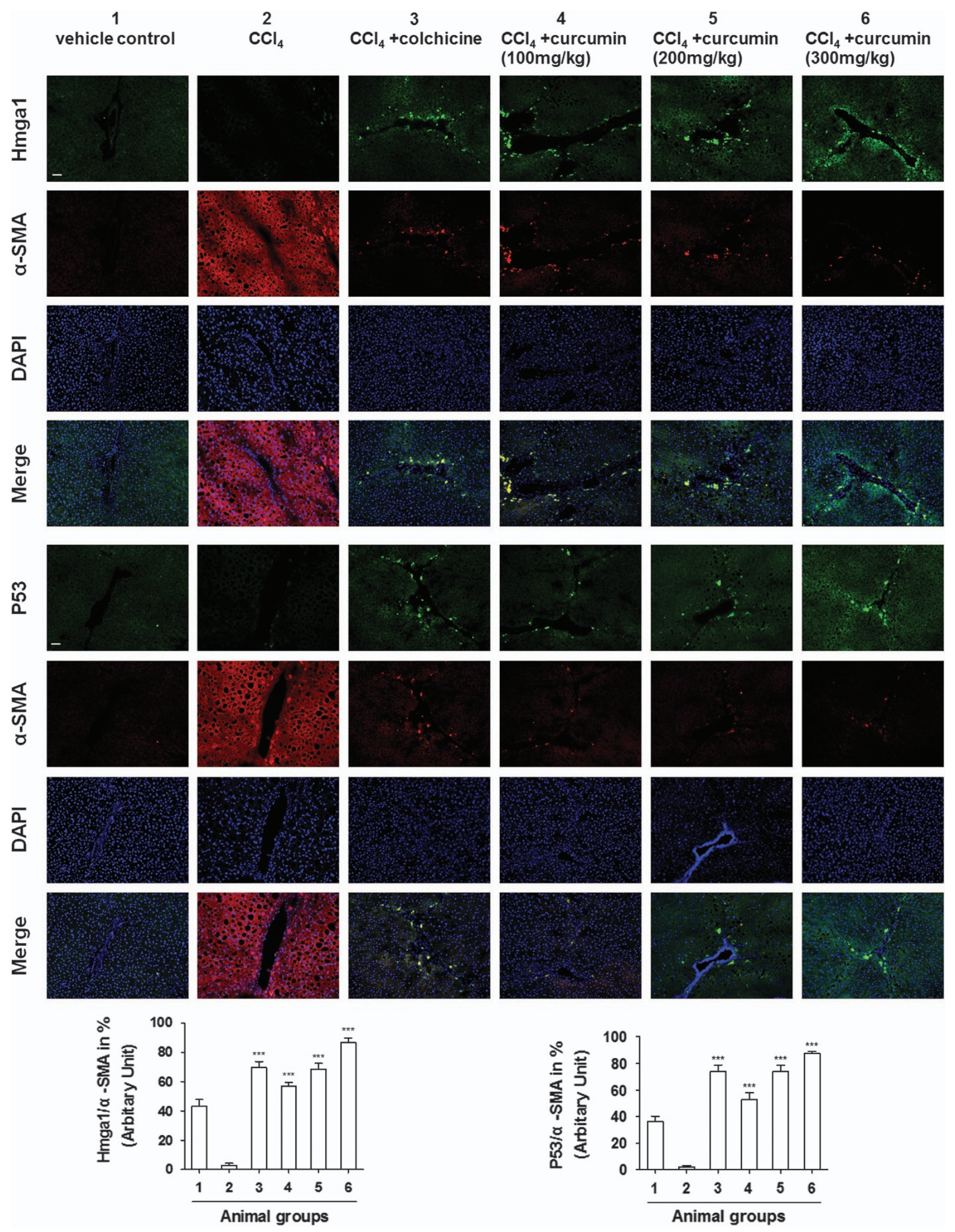


a

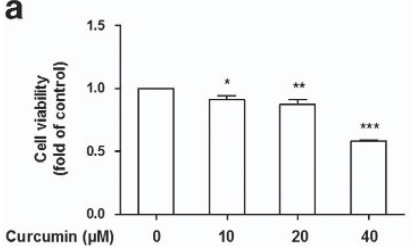

b

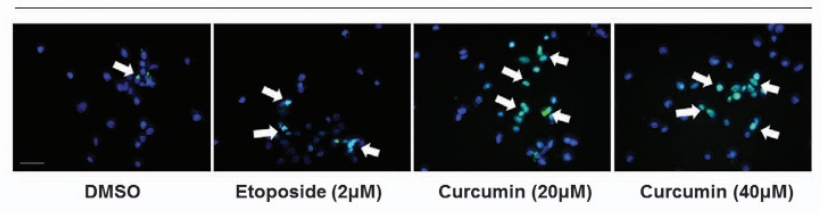

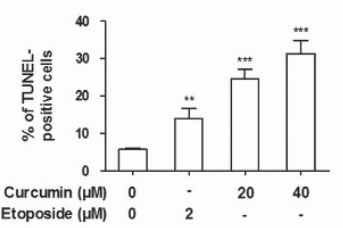

d

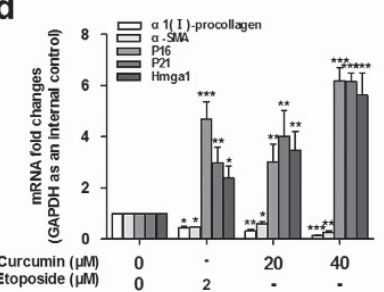

c

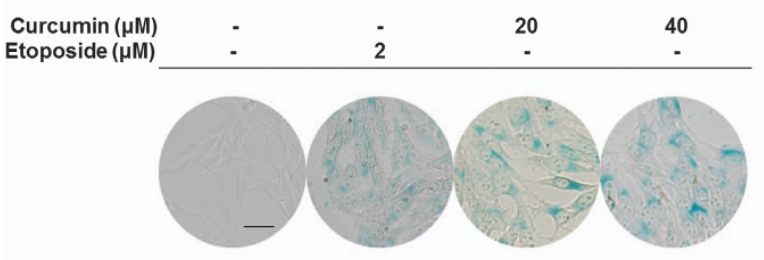

e

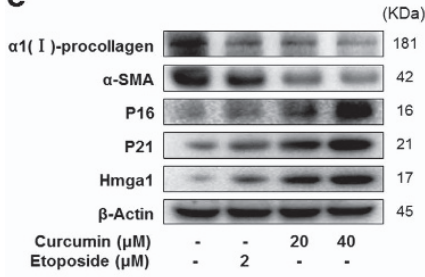

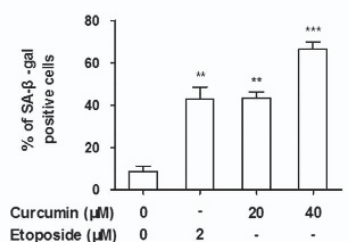

f

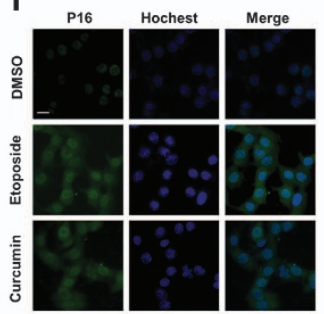

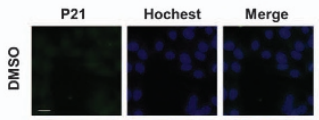

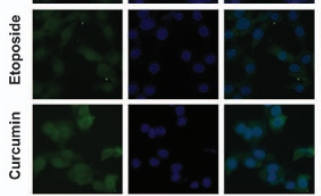

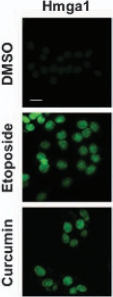
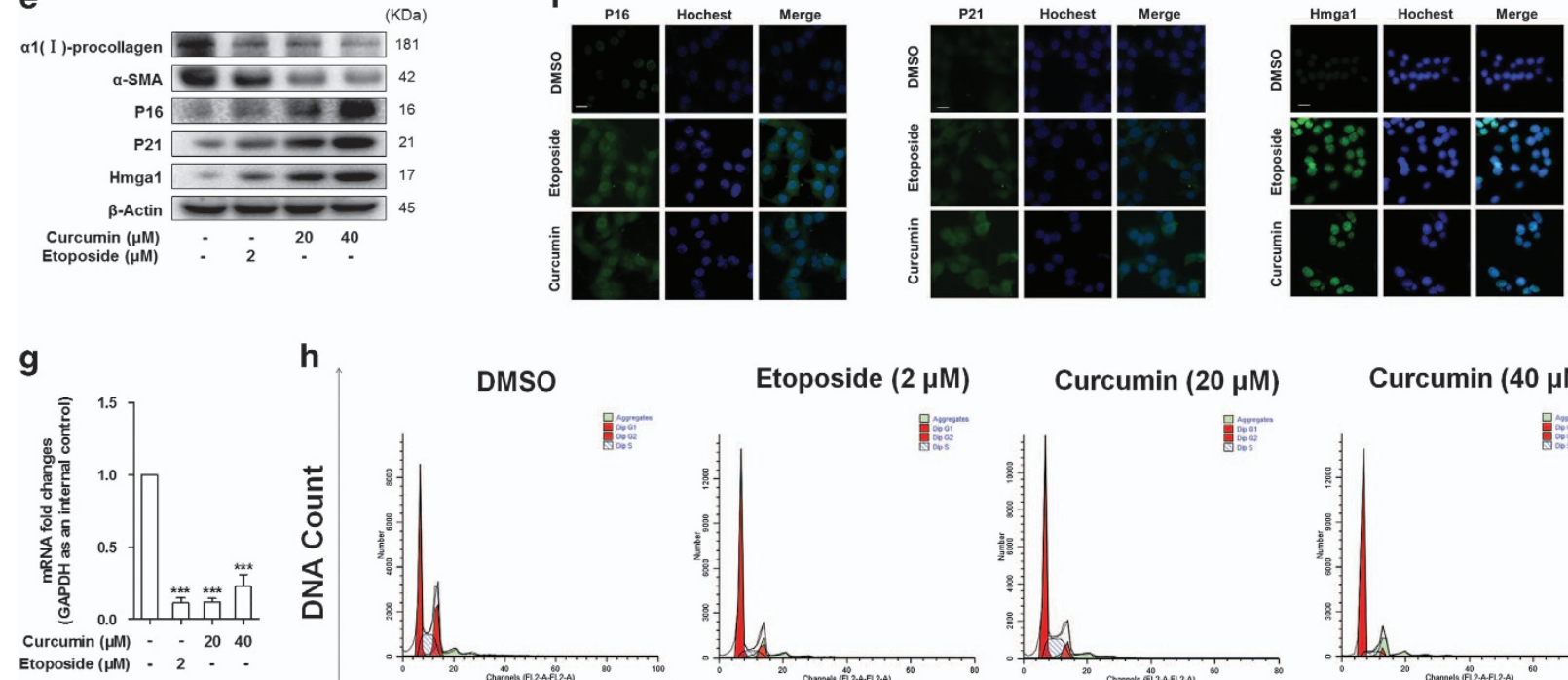

h $\quad$ DMSO

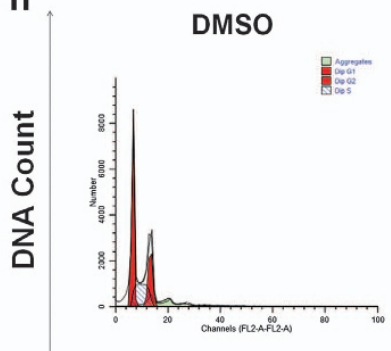

Etoposide $(2 \mu \mathrm{M})$

Curcumin $(20 \mu \mathrm{M})$

Curcumin $(40 \mu \mathrm{M})$
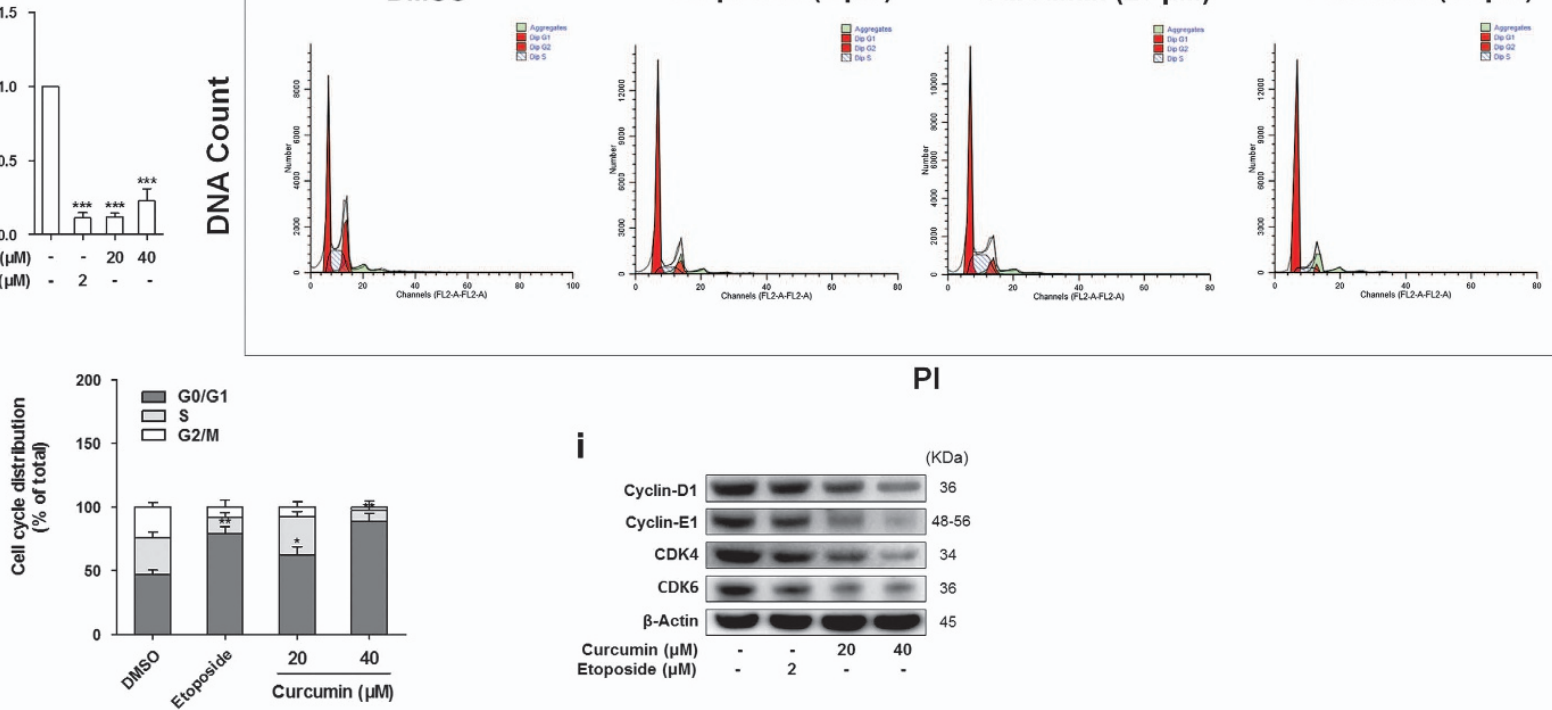

PI

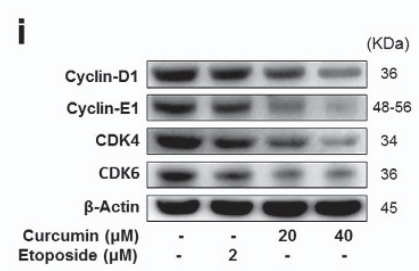

Figure 2 Curcumin promoted senescence of activated HSC in vitro. HSCs were treated with DMSO $(0.02 \%$, w/v), etoposide or curcumin at indicated concentrations for $24 \mathrm{~h}$. (a) Cell Count Kit-8 analysis of the ability of cell proliferation. ${ }^{*} P<0.05$ versus DMSO, ${ }^{* *} P<0.01$ versus DMSO, ${ }^{* * *} P<0.001$ versus DMSO. (b) TUNEL staining for evaluating apoptosis. Green fluorescence indicates apoptotic cells. Percentages of TUNEL-positive cells were determined. Data are represented as mean \pm S.D. ${ }^{* \star} P<0.01$ versus DMSO, ${ }^{* * \star} P<0.001$ versus DMSO. Scale bar, $50 \mu \mathrm{m}$. (c) Senescence $\beta$-galactosidase staining analysis. Percentages of cells positive for SA- $\beta$-Gal were scored; the averages \pm S.D. of data from at least three separate experiments are shown. ${ }^{* \star} P<0.01$ versus DMSO, ${ }^{* \star *} P<0.001$ versus DMSO. Scale bar, $200 \mu \mathrm{m}$. (d) Real-time PCR analyses of genes relevant to fibrogenesis and senescence, including $\alpha$-SMA, $\alpha 1(\mathrm{I})$-procollagen and P16, P21 and Hmga1, respectively. Data are represented as mean \pm S.D. Significance: ${ }^{\star} P<0.05$ versus DMSO, ${ }^{* \star} P<0.01$ versus DMSO, ${ }^{* \star *} P<0.001$ versus DMSO. (e) Western blot analyses of protein expression of fibrogenic molecules $\alpha$-SMA, $\alpha 1(\mathrm{I})$-procollagen and senescence molecules P16, P21 and Hmga1. (f) Immunofluorescence using antibody against P16, P21, Hmga1. Hoechst reagent was used to stain the nucleus. Scale bar, $10 \mu \mathrm{m}$. (g) Real-time PCR analysis of the mRNA levels of telomerase (TERT). Data are represented as mean \pm S.D. ${ }^{* \star *} P<0.001$ versus DMSO. (h) Cell cycle analysis by flow cytometry. Percentages of cell cycle distributions were determined. Data are represented as mean \pm S.D. ${ }^{*} P<0.05$ versus DMSO, ${ }^{* \star} P<0.01$ versus DMSO. (i) Western blot analyses of cell cycle-regulatory proteins cyclin D1, cyclin E1, CDK4 and CDK6 

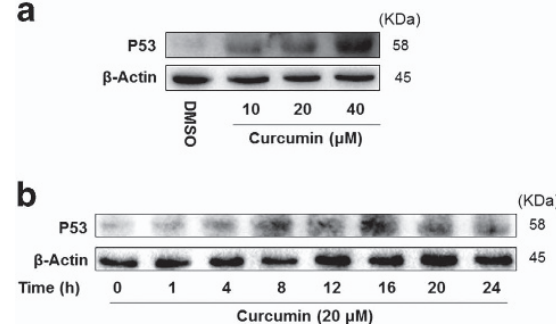

d

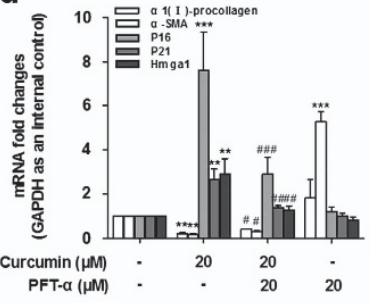

e

g

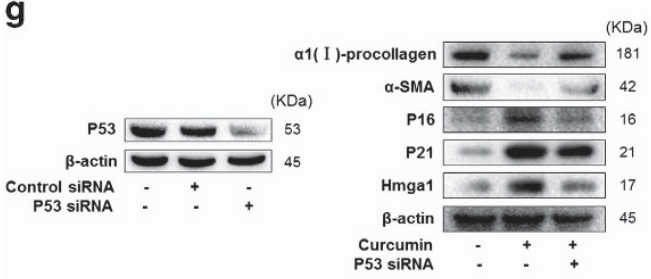

C
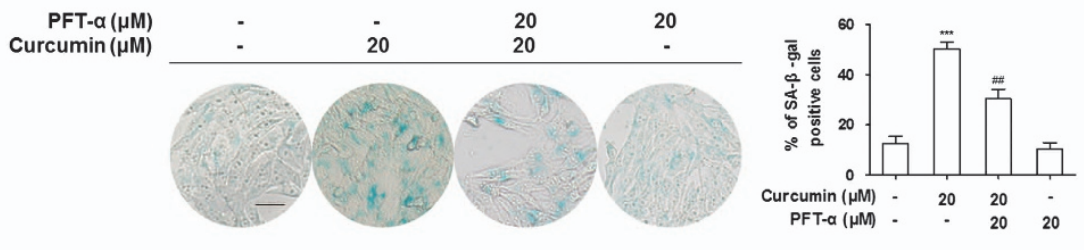

f

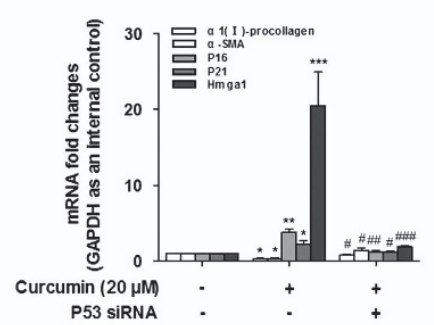

h
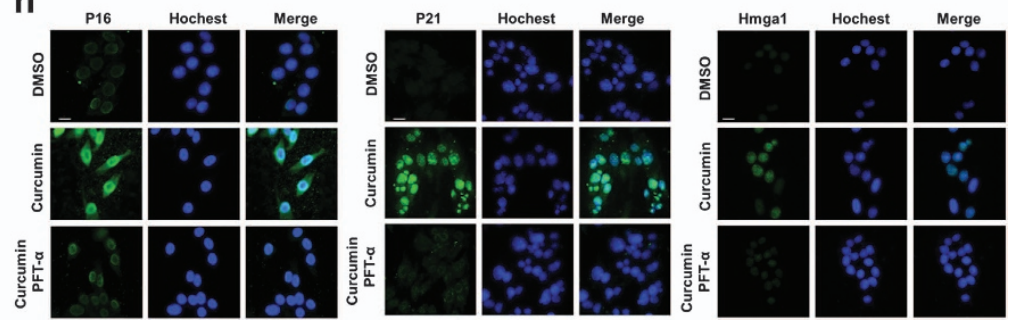

Figure 3 Curcumin induced senescence of activated HSC via a P53-dependent mechanism. (a and $\mathbf{b}$ ) Western blot analyses of protein expression of P53. HSCs were treated with DMSO $(0.02 \%, \mathrm{w} / \mathrm{v})$ or curcumin at the indicated concentrations for $24 \mathrm{~h}$ or at $20 \mu \mathrm{M}$ for the indicated time periods. (c) Senscence $\beta$-galactosidase staining analysis. HSCs were treated with DMSO $(0.02 \%$, w/v), curcumin $(20 \mu \mathrm{M})$ and/or PFT- $\alpha(20 \mu \mathrm{M})$ for $24 \mathrm{~h}$. PFT- $\alpha$ : a specific P53 inhibitor. Percentages of cells positive for SA- $\beta$-Gal were scored; the averages \pm S.D. of data from at least three separate experiments are shown. ${ }^{* * *} P<0.001$ versus DMSO, ${ }^{\# \#} P<0.01$ versus curcumin. Scale bar, $200 \mu \mathrm{m}$ (d and $\left.\mathbf{e}\right)$ Real-time PCR analyses of genes relevant to fibrogenesis and senescence, including $\alpha$-SMA, $\alpha 1$ (I)-procollagen and P16, P21, Hmga1, respectively. Data are represented as mean \pm S.D. Significance: ${ }^{*} P<0.05$ versus DMSO or control siRNA, ${ }^{* *} P<0.01$ versus DMSO or control siRNA, ${ }^{* \star *} P<0.001$ versus DMSO or control siRNA, ${ }^{\#} P<0.05$ versus curcumin, ${ }^{\# \#} P<0.01$ versus curcumin, ${ }^{\# \#} P<0.001$ versus curcumin. (f and $\mathbf{g}$ ) Western blot analyses of protein expression of fibrogenic molecules $\alpha$-SMA, $\alpha 1$ (I)-procollagen and senescence molecules P16, P21, Hmga1. (h) Immunofluorescence using antibody against P16, P21 and Hmga1. Hoechst reagent was used to stain the nucleus. Scale bar, $10 \mu \mathrm{m}$

with curcumin alone (Figure 4a). Low levels of serum alanine aminotransferase, aspartate aminotransferase and alkaline phosphatase in curcumin-treated mice were also elevated by suppression of P53 (Figure 4b). At the same time, knockdown of P53 significantly upregulated the levels of serum hyaluronic acid, laminin, procollagen type III and hydroxyproline (Figure 4c). To further confirm the above results, primary HSCs were isolated and directly used for western blot analysis of activated HSC markers a1(I)-procollagen and a-SMA. The results demonstrated that interference of P53 significantly elevated the expression of $a 1$ (I)-procollagen and $a$-SMA, suggesting that the effect of curcumin was at least partially reversed (Figure $4 \mathrm{e}$ ). We then determined whether the P53 pathway contributed to curcumin promotion of P16, P21 and Hmga1 expression in HSCs in vivo. Liver tissues were used for fluorescent staining of Hmga1 and $\gamma \mathrm{H} 2 \mathrm{AX}(\mathrm{a}$ marker of DNA damage) with $a$-SMA, respectively, by double fluorescent staining (Figure 4d). Furthermore, HSCs were isolated from the liver and directly used for western blot analyses of P16, P21, Hmga1 and $\gamma \mathrm{H} 2 \mathrm{AX}$ (Figure 4e). The results indicated that curcumin markedly increased the number of senescence marker-positive HSCs, which was partially reversed by Ad.shP53. Similar results were obtained by western blot analyses of P16, P21 and Hmga1 in primary HSCs. These data collectively suggested that the P53 pathway was involved in curcumin induction of P53 expression in HSCs in vivo.

Curcumin activation of PPAR $y$ promoted transactivation of P53. Previous reports indicated that curcumin inhibited HSC proliferation by inducing gene expression of PPARy in activated HSCs in vitro. ${ }^{15}$ Our current study validated this observation and showed that curcumin elevated the levels of PPARy (Figure 5a). We here assumed that activation of PPAR $y$ by curcumin might stimulate the gene expression of P53, which in turn stimulated the senescence of activated HSCs and ultimately led to reduction of live fibrosis. To test this assumption, determination of PPARy distribution by western blot analyses revealed that curcumin dosedependently increased PPARy abundance in nucleus and decreased its abundance in the cytoplasm (Figure 5b). Immunofluorescence double staining showed that PPARy 
a

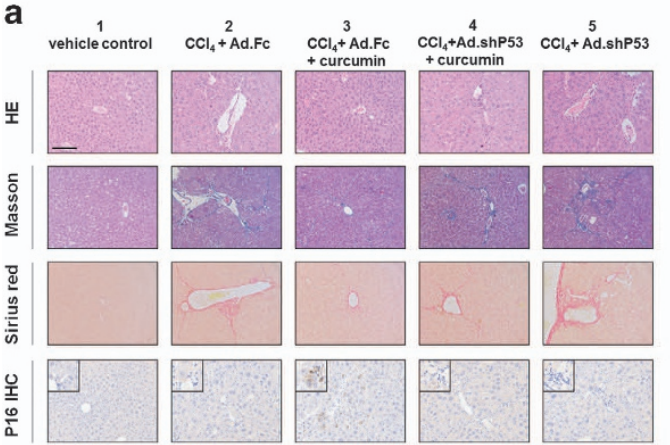

b

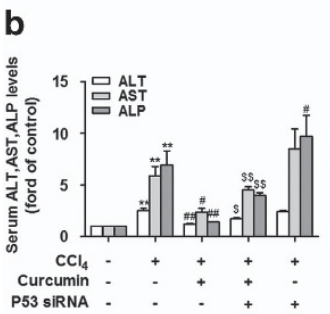

C d
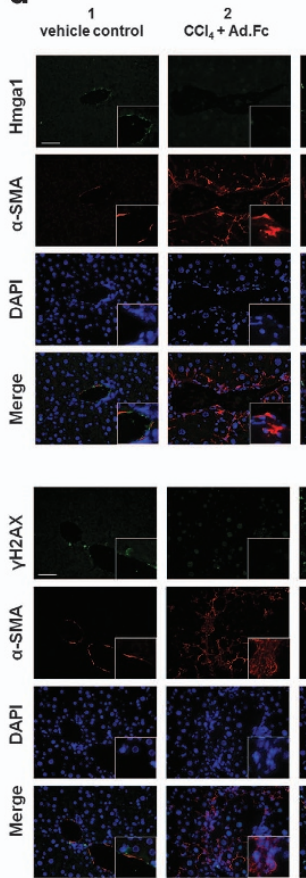

$\mathrm{CCl}_{4}{ }^{3} \mathrm{Ad} \cdot \mathrm{Fc}$
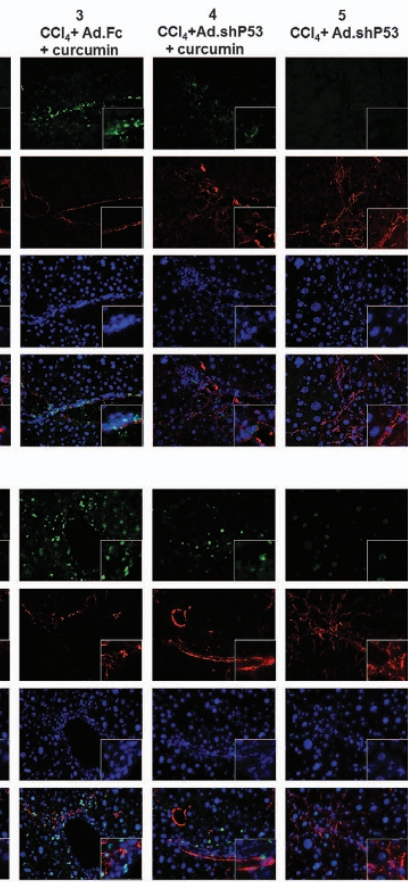

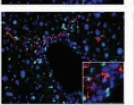

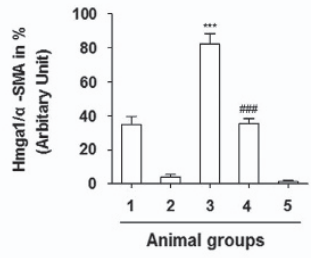
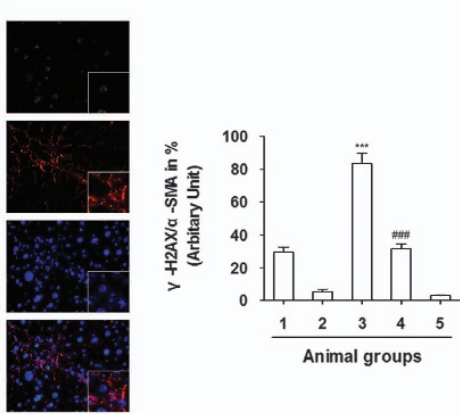

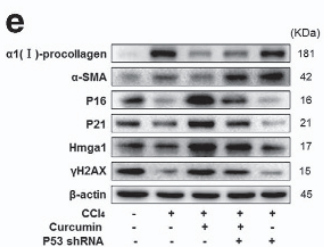

Figure 4 P53 mediated curcumin-induced senescence of activated HSC in vivo. Mice were randomly separated into five groups: group 1, vehicle control (no CCl, no treatment); group 2 (with $\mathrm{CCl}_{4}+\mathrm{Ad} . \mathrm{Fc}$ ); group 3 (with $\mathrm{CCl}_{4}+$ curcumin+Ad.Fc); group 4 (with $\mathrm{CCl}_{4}+$ curcumin+Ad.shP53); and group 5 (with $\mathrm{CCl}_{4}+\mathrm{Ad}_{\text {. }}$. $\mathrm{PP} 53$ ). Mice were injected with $\mathrm{CCl}_{4}\left(0.5 \mathrm{ml}\right.$ per $100 \mathrm{~g}$ body weight, i.p., twice a week) or curcumin ( $300 \mathrm{mg} / \mathrm{kg}$ body weight, once per 2 days) for 8 weeks. Ad.shP53 or Ad.Fc ( $2.5 \times 10^{7} \mathrm{pfu} / \mathrm{g} \mathrm{body} \mathrm{weight,}$ once every 2 weeks) was injected into the tail vein. Ad.Fc was used as a control virus. (a) Liver sections were stained with hematoxylin and eosin, Masson reagents, sirius red and P16. Representative photographs are shown. Scale bar, $100 \mu \mathrm{m}$. (b and c) Determination of serum alanine aminotransferase (ALT), aspartate aminotransferase (AST), alkaline phosphatase (ALP), hyaluronic acid (HA), laminin (LN), procollagen type III (PCIII) and hydroxyproline levels. Data are represented as mean \pm S.D. Significance: ${ }^{* *} P<0.01$ versus group $1,{ }^{* *} P<0.001$ versus group $1,{ }^{\#} P<0.05$ versus group $2,{ }^{\# \#} P<0.01$ versus group $2,{ }^{\# \# \#} P<0.001$ versus group $2,{ }^{\$} P<0.05$ versus group 3 , ${ }^{\$} P<0.01$ versus group 3. (d) Liver sections were stained with immunofluorescence by using antibodies against Hmga1 and $\gamma \mathrm{H} 2 \mathrm{AX}$ (a marker of DNA damage). Antibody against $\alpha$-SMA was used to specifically stain HSCs, and DAPI to stain the nucleus. Bar graphs showed the percentage quantitation of fluorescent images of Hmga1 or $\gamma \mathrm{H} 2 \mathrm{AX}$-positive cells in total activated HSCs ( $\alpha$-SMA as a marker) using the software Image $\mathrm{J}$ as shown in (d). ${ }^{* * *} P<0.001$ versus group 2, ${ }^{\# \# \#} P<0.001$ versus group 3 . Scale bar, $50 \mu \mathrm{m}$. (e) Western blot analyses of a-SMA, $\alpha 1(\mathrm{I})$-procollagen, P16, P21, Hmga1 and $\gamma \mathrm{H} 2 \mathrm{AX}$ protein levels in isolated HSCs

accumulated in nucleus upon curcumin treatment (Figure 5c). The interaction of PPARy with DNA sequence was also significantly increased by curcumin as demonstrated by the EMSA data (Figure 5d). To test whether PPARy interacted with P53 to regulate the senescence of activated HSCs, cells were transiently transfected with the P53-inducible luciferase reporter plasmid pP53-TA-luc, and then were treated with the PPAR $y$ antagonist PD68235 $(10 \mu \mathrm{M})$ or PPAR $y$ agonist 15dPGJ2 $(10 \mu \mathrm{M})$ prior to the addition of curcumin. Luciferase assays demonstrated that forced expression of PPAR $y$ mimicked the curcumin induction of luciferase activity in a dose-dependent manner (Figure 5e). These results indicated that curcumin activation of PPARy induced the gene expression of P53 in activated HSCs in vitro.

Activation of PPARy is required for curcumin induction of P53-dependent senescence of activated HSCs. To further test the role of PPARy in curcumin induction of HSC senescence, cultured HSCs were pretreated with 15d-PGJ2
$(10 \mu \mathrm{M})$ or PD68235 $(10 \mu \mathrm{M})$ for $1 \mathrm{~h}$ prior to addition of curcumin $(20 \mu \mathrm{M})$ for an additional $24 \mathrm{~h}$. Treatment with $15 \mathrm{~d}-$ PGJ2 induced a high accumulation of SA- $\beta$-gal ${ }^{+} \mathrm{HSCs}$, compared with the cells treated with curcumin alone (Figure 6a). We found that curcumin downregulation of $a$-SMA and $a 1$ (I)-procollagen, and upregulation of P16, P21 and Hmga1 were all strengthened by 15d-PGJ2 (Figures 6b and c). As expected, immunofluorescence double staining showed that the senescence markers P16, P21 and Hmga1 were highly expressed in HSCs upon 15d-PGJ2 treatment (Figure 6d). Furthermore, pretreatment of cells with PD68235 weakened the pro-senescence effects of curcumin (Figure 6e), but PD68235 abolished curcumin inhibition of $a$-SMA and a1(I)-procollagen and abrogated curcumin induction of P16, P21 and Hmga1 expression at both mRNA and protein levels (Figures $6 f$ and $g$ ). Immunofluorescence double staining detecting the expression of senescence markers of P16, P21 and Hmga1 provided consistent results (Figure 6h). Moreover, we also examined the levels of P53 in 
a

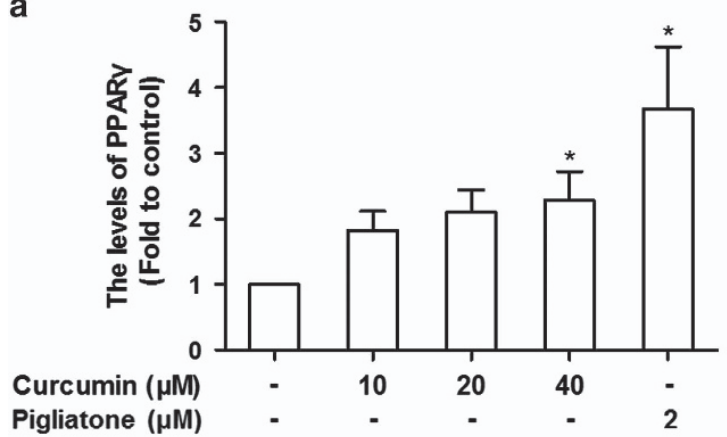

b

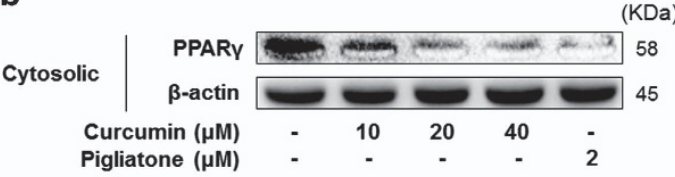

C

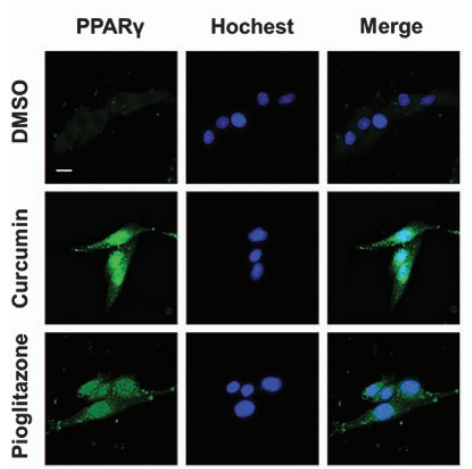

d

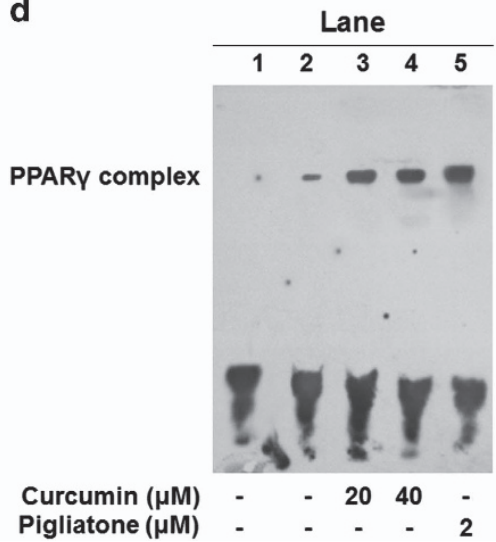

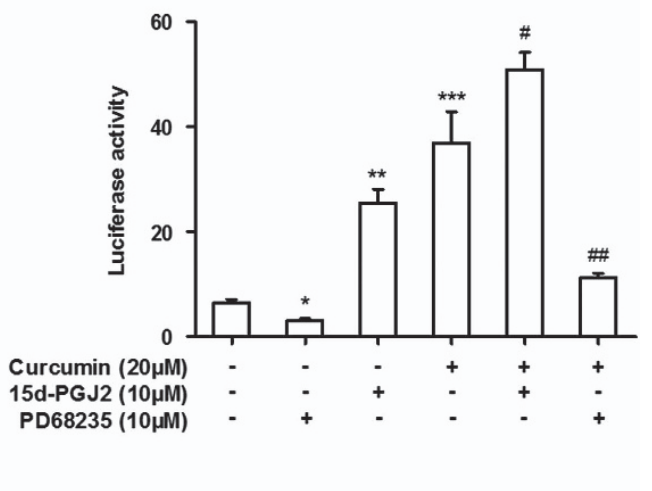

Figure 5 Curcumin activation of PPAR $\gamma$ promoted transactivation of P53. HSCs were treated with DMSO $(0.02 \%$, w/v), curcumin and pigliatone at indicated concentrations for $24 \mathrm{~h}$. (a) The levels of PPAR $\gamma$ in culture HSC were examined by ELISA. Data are represented as mean \pm S.D. Significance: ${ }^{*} P<0.05$ versus DMSO. (b) Western blot analyses of protein abundance of PPAR $\gamma$ in the cytoplasm and nucleus, respectively. (c) Immunofluorescence using antibody against PPAR . Hoechst reagent was used to stain the nucleus. Scale bar, $10 \mu \mathrm{m}$. (d) EMSA for examining the binding capacity of PPAR $\gamma$ to DNA sequences. Lane 1 indicates samples treated with probe alone. Lane 2 was samples treated with DMSO without curcumin, Lane 3 was samples treated with curcumin $(20 \mu \mathrm{M})$, Lane 4 was samples treated with curcumin $(40 \mu \mathrm{M})$, Lane 5 was samples treated with Pigliatone $(2 \mu \mathrm{M})$. (e) Passaged HSC were transfected with the pP53-Luc. Cells were then pretreated with or without 15d-PGJ2 (10 $\mu \mathrm{M})$, PD68235 (10 $\mu \mathrm{M})$, for $1 \mathrm{~h}$ prior to addition of curcumin $(20 \mu \mathrm{M})$ for an additional $24 \mathrm{~h}$. Luciferase activities are expressed as relative units after Renilla luciferase reporter normalization $(n=6)$. Data are represented as mean \pm S.D. Significance: ${ }^{*} P<0.05$ versus DMSO, ${ }^{* \star} P<0.01$ versus DMSO. ${ }^{* \star *} P<0.001$ versus DMSO, ${ }^{\#} P<0.05$ versus curcumin, ${ }^{\# \#} P<0.01$ versus curcumin

the presence of PD68235 or 15d-PGJ2. The results showed that curcumin induction of P53 expression was elevated by 15d-PGJ2 treatment (Figures 6b-d). In contrast, PD68235 inhibited the stimulatory effect of curcumin on P53 expression (Figures 6f-h). These discoveries collectively suggested that PPARy played a key role in curcumin induction of HSC senescence.

\section{Discussion}

The phenotype of senescent cells is characterized by a terminal cell cycle arrest, expression of SA- $\beta$-gal (a lysosomal enzyme) and induction of p16 and p21. The process of senescence was first described as a state of terminal proliferative exhaustion ${ }^{26}$ and was mediated by progressive telomere shortening and activation of a DNA damage response. Prior studies have discovered the existence of senescent activated HSCs during the development of fibrosis. It is considered that the senescence of activated HSCs is a spontaneous phenomenon and limits the fibrogenic response to acute tissue damage. Senescent activated HSCs reduced the secretion of ECM components, increased the secretion of ECM-degrading enzymes and enhanced immune surveillance. ${ }^{6,27}$ Therefore, the senescence of activated HSCs induced by drugs may be an effective method for hepatic fibrosis treatment.

In previous studies, we have studied the mechanism of curcumin underlying its antifibrotic efficacy in depth. Growing evidence has shown that curcumin induces HSC apoptosis and our current results proved this point. The aim of the present study was to confirm whether curcumin had a regulatory effect on HSC senescence. Our results suggested that curcumin could inhibit cell proliferation and regulate the senescence of activated HSCs. On the one hand, our present animal experiments demonstrated that the senescence marker Hmga1 was co-localized with the marker of activated HSCs in rat fibrotic liver and that the number of activated HSCs was directly opposite to the level of Hmga1. On the other hand, SA- $\beta$-gal staining provided the evidence that senescent HSCs could be detected in curcumin-treated HSCs in vitro. Although P16 and P21 serve as the regulators of cell cycle, increasing evidence has demonstrated that $\mathrm{P} 16$ and $\mathrm{P} 21$ are upregulated in senescent cells. ${ }^{28,29}$ Herein, we used them as the markers of cellular senescence. In this report, curcumin increased the gene expression of senescence markers P16, P21 and Hmga1 in cultured HSCs. However, the mRNA and protein 
levels of $a$-SMA and $a 1(\mathrm{I})$-procollagen were significantly decreased by the curcumin treatment. These discoveries supported the possibility that induction of HSC senescence could treat liver fibrosis.

Cell cycle arrest and telomerase system dysfunction are the critical features of cellular senescence. ${ }^{30}$ We herein found that curcumin blocked cell cycle arrest at the G0/G1 checkpoint. Cell cycle progression is the result of the interaction between cyclins and their inhibitors CDKs. ${ }^{31}$ Consistently, our current data indicated that curcumin reduced the protein abundance of the G0/G1 phase-related cyclins/CDKs. At the same time, real-time PCR analyses showed that telomerase activity was decreased by curcumin treatment. It has been well-known that cellular senescence is accompanied with the reduction in telomerase activity and telomere length. ${ }^{32}$ Herein, our results strengthened the observation of induction of HSC senescence by curcumin, which could be a strategy for cell-fate regulation in HSCs.

Further studies revealed that the tumor suppressor P53 played an important role in induction of cellular senescence by curcumin. This raised a question of how to control HSC senescence by curcumin. In the present study, we found that curcumin dose- and time-dependently promoted the expression of P53, but the P53 inhibitor pifithrin-a (PFT- $a$ ) or P53 siRNA weakened the pro-senescence effects of curcumin in cultured HSCs. Besides, to provide further evidence for a functional role of P53 activation in the senescence of activated $\mathrm{HSCs}$ in vivo, mice were subjected to administration of Ad.Fc, curcumin plus Ad.Fc, curcumin plus Ad.shP53 or Ad.shP53. We found that curcumin's promotion effect of HSC senescence could be reversed by Ad.shP53. This result was consistent with other prior observations. In many cell types, P53 has been found to regulate the cell cycle arrest and cellular senescence. ${ }^{25,33}$ Therefore, the induction of HSC senescence by $\mathrm{P} 53$ could be a therapeutic target for reduction of HSC activation and inhibition of profibrogenic behaviors of activated HSCs.

Cellular senescence mediated by $\mathrm{P} 53$ is influenced by multiple signaling pathways, such as IL-22/STAT3 pathway. ${ }^{34}$ There is another question of how to regulate the expression of P53 by curcumin in induction of HSC senescence. In this study, our evidence showed that curcumin induced the expression of P53 through activation of PPAR $y$ in activated HSCs. The previous studies have shown that the expression of PPAR $y$ was diminished when quiescent HSCs become activated. At the same time, activation of PPAR $y$ was required for curcumin to reduce cell proliferation, induce apoptosis and suppress ECM gene expression. ${ }^{15}$ In the present study, we found that curcumin activated PPARy and promoted the nuclear translocation of PPAR $\gamma$. Moreover, binding to DNA sequence and transactivated P53 by PPARy were all significantly enhanced in curcumin-treated HSCs. Our further experiments revealed that PPARy played a key role in curcumin induction of HSC senescence. PPARy agonist $15 d-$ PGJ2 enhanced the curcumin induction of expression of senescence markers. Besides, PPARy antagonist PD68235 abrogated this stimulatory effect. We also examined the effect of PPARy on the expression of P53 in senescent HSCs. Real-time PCR, western blot and immunofluorescence staining consistently showed that curcumin could promote the expression of P53 by activating PPARy. Taken together, these data revealed that activation of PPAR $y$ causally stimulated P53 expression, which critically led to the cell growth arrest and senescence of activated HSCs.

In summary, the aggregate data in this study demonstrated that curcumin regulated senescence by inducting PPAR $\gamma /$ P53 pathway in activated HSCs (Figure 6i), indicating that induction of cellular senescence could be a new strategy for inhibiting fibrogenic properties in activated HSCs by curcumin. These findings provided novel molecular basis for the development of curcumin as a promising antifibrotic agent for liver fibrosis.

\section{Materials and Methods}

Reagents and antibodies. The following compounds were used in this study: curcumin, compounds 15d-PGJ2 and PD68235 (Sigma, St. Louis, MO, USA); Etoposide (Selleckchem, Houston, TX, USA); P53 inhibitor PFT- $\alpha$ (Nanjing EnoGene Biotech Co., Ltd, Nanjing, China). All these compounds were dissolved in dimethylsulfoxide (DMSO; Sinopharm Chemical Reagent Co., Ltd, Shanghai, China) for experiments. The primary antibodies were used in this study: P16, P53, cyclin D1, cyclin E1, CDK4, CDK6, PPAR- $\gamma, \gamma \mathrm{H} 2 \mathrm{AX}$ and $\beta$-actin (Cell Signaling Technology, Danvers, MA, USA); P21 (Santa Cruz Biotechnology, Santa Cruz, CA, USA); Hmga1 (Abcam Technology, Abcam, Cambridge, UK); $\alpha 1$ (I)-procollagen and $\alpha$-SMA (Epitomics, San Francisco, CA, USA).

Experimental animal procedures. All experimental procedures were approved by the institutional and local committee on the care and use of animals of Nanjing University of Chinese Medicine (Nanjing, China), and all animals received humane care according to the National Institutes of Health (USA) guidelines. Male Sprague Dawley rats (200-250 g body weight) were obtained from Shanghai Slac Laboratory Animal (Shanghai, China). A mixture of carbon tetrachloride $\left(\mathrm{CCl}_{4}\right.$; $0.1 \mathrm{ml}$ per $100 \mathrm{~g}$ body weight) and olive oil $(1: 1(\mathrm{v} / \mathrm{v}))$ was used to induce liver fibrosis in rats. A total of 36 rats were randomly divided into six groups $(n=6)$. Group 1 was the vehicle control in which rats were not administrated $\mathrm{CCl}_{4}$ or curcumin but intraperitoneally (i.p.) injected with olive oil. Group 2 was the $\mathrm{CCl}_{4}$ group in which rats were i.p. injected with $\mathrm{CCl}_{4}$ without curcumin treatment. Group 3 was the positive control in which rats were injected with $\mathrm{CCl}_{4}$ and treated with colchicine (Yifeng Pharmacy, Nanjing, China) at $0.1 \mathrm{mg} / \mathrm{kg}$. Groups 4, 5 and 6 were treatment groups in which rats were i.p. injected with $\mathrm{CCl}_{4}$ and orally given curcumin

\footnotetext{
Figure 6 Activation of PPAR $y$ is required for curcumin induction of P53-dependent HSC senescence. HSCs were treated for $24 \mathrm{~h}$ with curcumin (20 $\mu \mathrm{M})$ with or without the pre-exposure to 15d-PGJ2 $(10 \mu \mathrm{M})$ and PD68235 $(10 \mu \mathrm{M})$ for $1 \mathrm{~h}$. (a and e) Senescence $\beta$-galactosidase staining analysis. Percentages of cells positive for SA- $\beta$-Gal were scored; the averages \pm S.D. of data from at least three separate experiments are shown. ${ }^{*} P<0.05$ versus DMSO, ${ }^{* *} P<0.01$ versus DMSO, ${ }^{* * \star} P<0.001$ versus DMSO, ${ }^{\# \#} P<0.01$ versus curcumin. Scale bar, $200 \mu \mathrm{m}$. (b and f) Real-time PCR analyses of genes relevant to fibrogenesis and senescence, including $\alpha$-SMA, $\alpha 1(\mathrm{I})$-procollagen and P16, P21, Hmga1 respectively. Data are represented as mean \pm S.D. Significance: ${ }^{\star} P<0.05$ versus DMSO, ${ }^{\star \star} P<0.01$ versus DMSO, ${ }^{* \star \star} P<0.001$ versus DMSO, ${ }^{\#} P<0.05$ versus curcumin, ${ }^{\#} P<0.01$ versus curcumin, ${ }^{\# \#} P<0.001$ versus curcumin. (c and $\mathbf{g}$ ) Western blot analyses of protein expression of fibrogenic molecules $\alpha$-SMA, $\alpha 1(\mathrm{I})$-procollagen and senescence molecules P16, P21 and Hmga1. (d and h) Immunofluorescence using antibody against P16, P21 and Hmga1. Hoechst reagent was used to stain the nucleus. Scale bar, $10 \mu \mathrm{m}$. (b-d, f-h) Real-time PCR, western blot and immunofluorescence analyses of the mRNA and protein levels of P53. Data are represented as mean \pm S.D. Scale bar, $10 \mu \mathrm{m}$. (i) PPAR $\gamma$ signaling played an important role in activated HSC senescence through transcriptionally upregulating P53 expression
} 
at 100, 200 and $300 \mathrm{mg} / \mathrm{kg}$, respectively. Rats in groups 2-6 were i.p. injected with $\mathrm{CCl}_{4}$ every other day for 8 weeks. Curcumin and colchicine were suspended in sterile phosphate-buffered saline (PBS) and given once daily by gavage during weeks $5-8$. The control animals in groups 1 and 2 were similarly handled, including i.p. injection with the same volume of olive oil and oral administration of the same volume of PBS. At the end of experiments, rats were killed after being anesthetized by i.p. injection with pentobarbital $(50 \mathrm{mg} / \mathrm{kg})$. A small portion of the liver was removed for histopathological and immunohistochemical studies.

Male ICR mice were randomly divided into five groups $(n=10)$ and given administration of Ad.Fc (a control adenovirus encoding $\lg G 2 \alpha$ Fc fragment), curcumin ( $300 \mathrm{mg} / \mathrm{kg}$, once per two days) plus Ad.Fc, curcumin plus Ad.shP53 (adenovirus encoding mouse P53 shRNA for inhibiting P53 pathway), or Ad.shP53, a

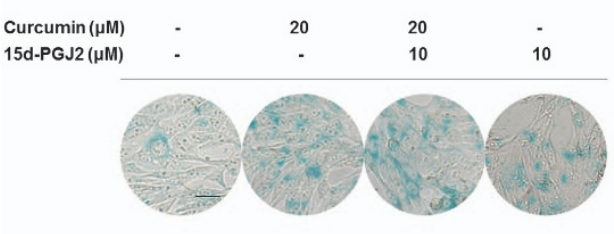

b

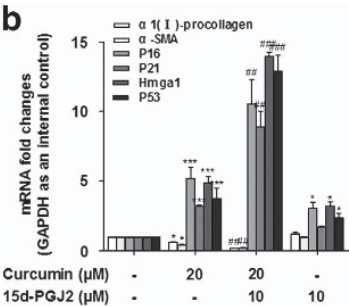

C

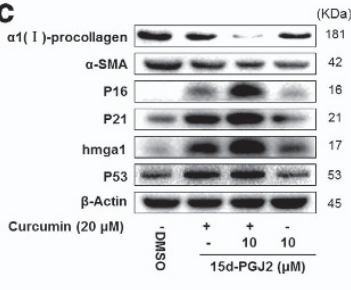

d
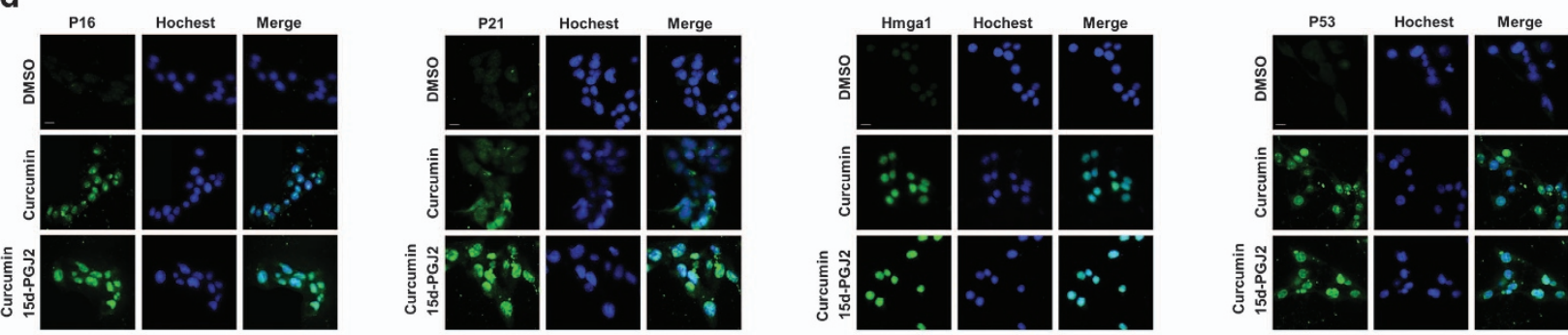

e
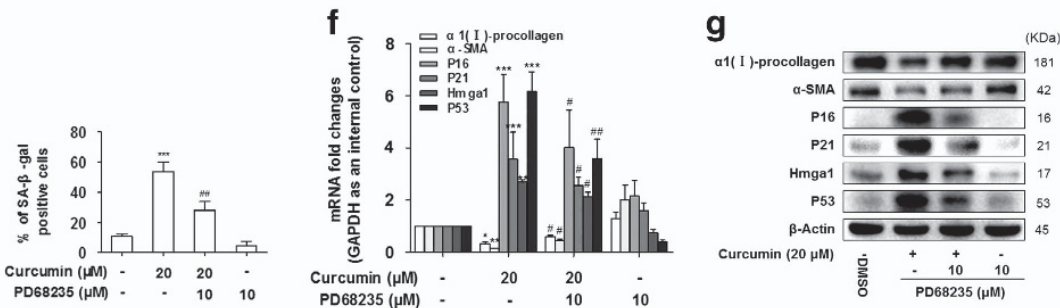

h
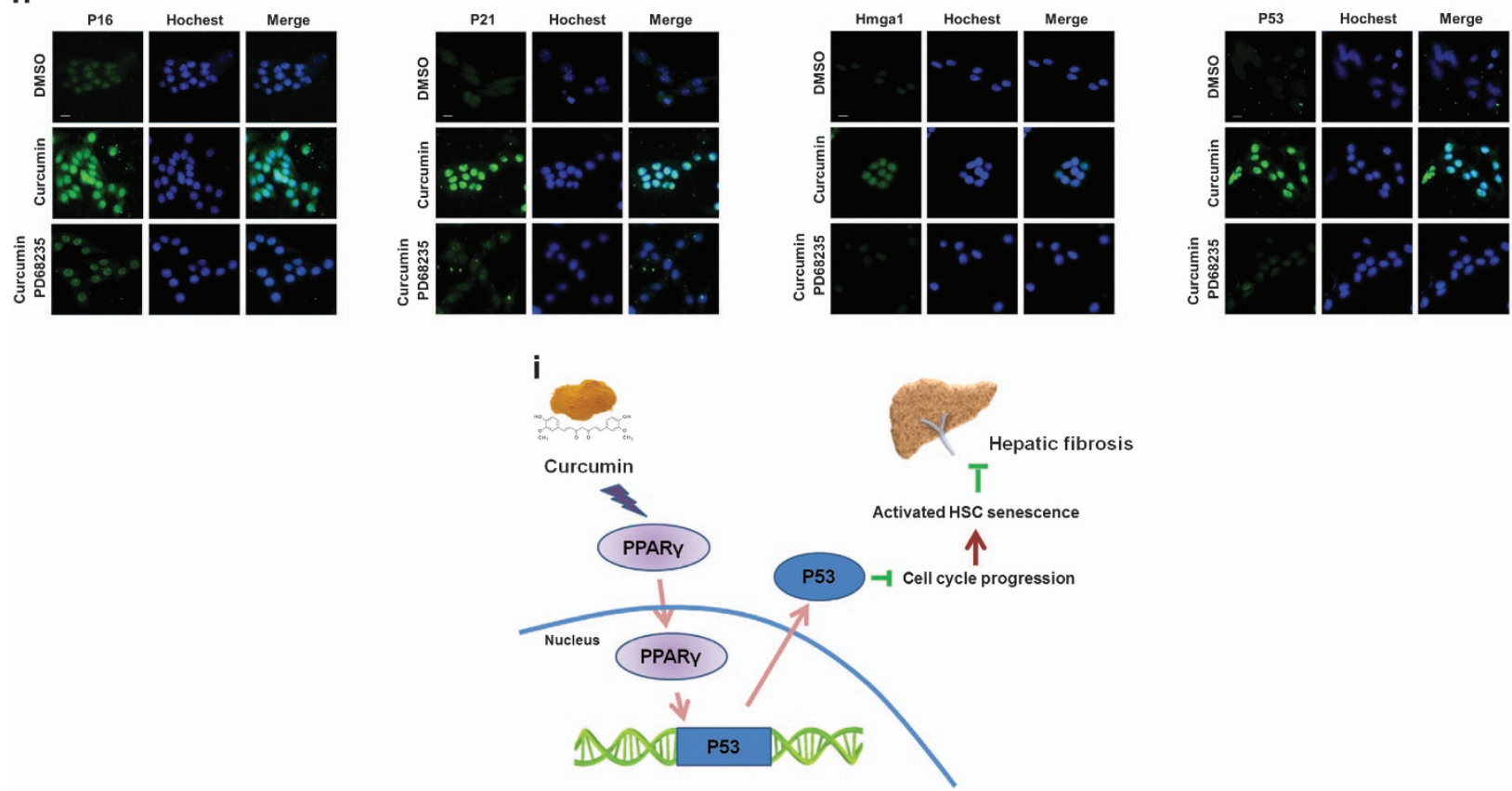
respectively, throughout the 8-week period of $\mathrm{CCl}_{4}$ treatment and the control group with no treatment. Adenoviruses $\left(2.5 \times 10^{7} \mathrm{pfu} / \mathrm{g}\right.$, once per 2 weeks) were injected into mice by tail vein. A mixture of carbon tetrachloride $\left(\mathrm{CCl}_{4} ; 0.5 \mathrm{ml}\right.$ per $100 \mathrm{~g}$ body weight) and olive oil $(1: 9(\mathrm{v} / \mathrm{v}))$ was used to induce liver fibrosis in mice by i.p. injection. After 8 weeks, liver were fixed in $4 \%$ buffered paraformaldehyde for histological analysis of liver fibrosis and immunostaining analysis or HSCs were isolated for western blot analysis.

Cell culture. HSC-T6 cell line was purchased from Cell Bank of Chinese Academy of Sciences (Shanghai, Chinese). Cells were cultured in Dulbecco's modified Eagle's medium (DMEM; Invitrogen, Grand Island, NY, USA) with 10\% fetal bovine serum (FBS; Sijiqing Biological Engineering Materials, HangZhou, China), $1 \%$ antibiotics and grown in a $95 \%$ air and $5 \% \mathrm{CO}_{2}$ humidified atmosphere at $37{ }^{\circ} \mathrm{C}$.

Immunofluorescence staining. Immunofluorescence staining with liver tissues or treated cells were performed as we previously reported. ${ }^{20} 4^{\prime}, 6$-Diamidino2-phenylindole (DAPI) was used to stain the nucleus in liver tissues. Hoechst reagent was used to stain the nucleus of HSCs in vitro. All the images were captured with the fluorescence microscope and representative images were shown. The software Image $J$ was used to quantitate the fluorescent intensity on the micrographs.

Cell proliferation assay and apoptosis assay. HSCs were treated with various reagents at indicated concentrations for $24 \mathrm{~h}$. Cell proliferation was evaluated using Cell Counting Kit-8 (Beyotime Biotechnology, Haimen, China) according to the protocols. Morphology of apoptotic HSCs was evaluated using TUNEL staining kits and DAPI staining kits (Nanjing Keygen Biotechnology Co., Ltd, Nanjing, China) according to the protocols. All these experiments were performed in triplicate.

Analysis of HSC senescence. HSC senescence was determined by the detection of SA- $\beta$-gal (senescence-associated $\beta$-galactosidase) activity using an SA- $\beta$-gal staining kit (Cell Signaling). Briefly, adherent cells were fixed with $0.5 \%$ glutaraldehyde in PBS for $15 \mathrm{~min}$, washed with PBS containing $1 \mathrm{mM} \mathrm{MgCl}_{2}$ and stained overnight in PBS containing $1 \mathrm{mM} \mathrm{MgCl}, 1 \mathrm{mg} / \mathrm{ml} \mathrm{X-Gal,} 5 \mathrm{mM}$ potassium ferricyanide and $5 \mathrm{mM}$ potassium ferrocyanide. All the images were captured with a light microscope and representative images were shown. Results were from triplicate experiments.

Cell transfection with P53 siRNA. P53 siRNA (Santa Cruz Biotechnology; sc-45917) of $5 \mu \mathrm{g}$ was added to $150 \mu \mathrm{l}$ medium without serum and antibiotic and incubated at room temperature for $5 \mathrm{~min}$. LipofectAMINE reagent (Life Technologies, Grand Island, NY, USA) of $3 \mu \mathrm{l}$ was added to $150 \mu \mathrm{l}$ medium without serum and antibiotics and incubated at room temperature for $5 \mathrm{~min}$. The above two solutions were mixed well at room temperature for $20 \mathrm{~min}$ and about $300 \mu \mathrm{l}$ transfection complex was obtained. Cells were incubated with the transfection complex solution at $37^{\circ} \mathrm{C}$ for $8 \mathrm{~h}$, and then were re-incubated in complete medium at $37^{\circ} \mathrm{C}$ for an additional $16 \mathrm{~h}$. Control siRNA (Santa Cruz Biotechnology; sc-37007) is a nontargeting 20-25 nt siRNA designed as a negative control.

Cell cycle analysis by flow cytometry. Distribution of cell cycle was determined by PI staining and flow cytometry analysis. HSCs were seeded in sixwell plates and cultured in DMEM supplemented with 10\% FBS for $24 \mathrm{~h}$, and then were treated with DMSO, etoposide and curcumin at indicated concentrations for $24 \mathrm{~h}$. Cells were then harvested and fixed, and the cell cycle was then detected by the cellular DNA flow cytometric analysis kit (Nanjing Keygen Biotech Co., Ltd) according to the protocol. Percentages of cells within cell cycle compartments (GO/ G1, S and G2/M) were determined by flow cytometry (FACS Calibur; Becton, Dickinson and Company, Franklin Lakes, NJ, USA). The data were analyzed using the software Cell Quest. Results were from triplicate experiments.

Liver histopathology. Harvested liver tissues were fixed in $10 \%$ neutralbuffered formalin and embedded in paraffin. Liver slices of $50 \mu \mathrm{m}$ thick were prepared and stained with H\&E and Masson's trichrome stain by using standard methods. For sirius red collagen staining, thin sections were deparaffinized and stained with picro-sirius red for $1 \mathrm{~h}$ at room temperature. After washes, sections on the slides were dehydrated in $100 \%$ ethanol and in xylene, and then they were mounted in Permount. IHC staining was performed to detect the expression of P16 using an IHC accessory kit (Bethyl Laboratories, Montgomery, TX, USA).
Photographs were taken in a blinded fashion at random fields. Representative views of liver sections are shown.

Real-time PCR. Total RNA was prepared from treated HSCs using Trizol reagent (Sigma) following the protocol provided by the manufacturer. Real-time PCR was performed as we described previously. ${ }^{35}$ Glyceraldehyde phosphate dehydrogenase (GAPDH) was used as the invariant control. Fold changes in the mRNA levels of target genes related to the invariant control GAPDH were calculated according to the suggested method. ${ }^{36}$ The following primers of genes (GenScript, Nanjing, China) were used: $\alpha$-SMA: (forward) $5^{\prime}$-CCGACCGAATGCAGAAGG-3', (reverse) 5'-ACAGAGTATTTGCGCTCCGGA-3'; $\alpha 1$ (I)-procollagen: (forward) $5^{\prime}$-CC TCAAGGGCTCCAACGAG-3', (reverse) 5'-TCAATCACTGTCTTGCCCCA-3'; P16: (forward) 5'-CCGAGAGGAAGGCGAACTC-3', (reverse) 5'-GCTGCCCTGGCTAG TCTATCTG-3'; P21: (forward) 5'-GAGCAAAGTATGCCGTCGTC-3', (reverse) 5'-CT CAGTGGCGAAGTCAAAGTTC-3'; HMGA1: (forward) 5'-CAGGAAAAGGATGGGA CTGA-3', (reverse) 5'-CTTGTTCTTGCTTCCCTTCG-3'; P53: (forward) 5'-GCCAT CTACAAGAAGTCACAGC-3', (reverse) 5'-GATGATGGTAAGGATAGGTCGG-3'; GAPDH: (forward) 5'-GACATCAAGAAGGTGGTGAAGC-3, (reverse) 5'-TGTCAT TGAGAGCAATGCCAGC-3. Results were from triplicate experiments.

Western blot analyses. Whole-cell protein extracts were prepared from passaged HSCs. The protein levels were determined using a BCA assay kit (Pierce, Rockford, IL, USA). Proteins ( $50 \mu \mathrm{g} / \mathrm{well}$ ) were separated by SDS-polyacrylamide gel, transferred to a PVDF membrane (Millipore, Burlington, MA, USA), blocked with $5 \%$ skim milk in Tris-buffered saline containing $0.1 \%$ Tween 20 . Target proteins were detected by corresponding primary antibodies, and subsequently by horseradish peroxidase-conjugated secondary antibodies. Protein bands were visualized using chemiluminescence reagent (Millipore). Equivalent loading was confirmed using an antibody against $\beta$-actin. The levels of target protein bands were densitometrically determined using Quantity One 4.4.1. The variation in the density of bands was expressed as fold changes compared with the control in the blot after normalized to $\beta$-actin. Representative blots were from three independent experiments.

Enzyme-linked immunosorbent assay (ELISA). The levels of PPAR in HSCs were determined using an ELISA kit (Nanjing Jiancheng Bioengineering Institute, Nanjing, China) according to the protocol. Six duplicate wells were set up for each group. Results were from triplicate experiments.

Electrophoretic mobility shift assay (EMSA). Nuclear extracts from treated HSCs were prepared using the NE-PER Nuclear Protein Extraction Kit (Pierce) according to the protocol. The biotin-labeled PPAR $\gamma$ probe was prepared using an EMSA kit in accordance with the manufacturer's instructions (Pierce). The extracted nuclear protein $(10 \mathrm{mg})$ was incubated in a binding reaction mixture containing $1.5 \mathrm{ml} 10 \times$ binding buffer, $1.5 \mathrm{ml}$ poly $(\mathrm{dl}-\mathrm{dC})(1.0 \mathrm{mg} / \mathrm{ml})$ and $\mathrm{dd}_{2} \mathrm{O}$ to a final volume of $14.4 \mathrm{ml}$ for $20 \mathrm{~min}$ at room temperature. Then, the probe of $0.6 \mathrm{ml}(300 \mathrm{fmol})$ was added and incubated for $20 \mathrm{~min}$ at room temperature. Where indicated, $2 \mathrm{ml}$ of specific, cold-competitor oligonucleotides in $100 \times$ competing buffer was added before the labeled probe, and the reaction was incubated for $20 \mathrm{~min}$. Protein-DNA complexes were subjected to electrophoresis in a $6.5 \%$ acrylamide gel at $4{ }^{\circ} \mathrm{C}$ for $1 \mathrm{~h}$. The gels were transferred to the bonding membrane at room temperature for $40 \mathrm{~min}$. After crosslinking for $10 \mathrm{~min}$ with an ultraviolet crosslinking apparatus, the membrane was blocked, streptavidin-HRP labeled, washed again and equilibrated. Images were captured using the Gel Doc2000 system (Bio-Rad, Hercules, CA, USA).

Dual-luciferase reporter assay. The luciferase reporter plasmid P53 (pP53-TA-luc) was purchased from Beyotime Biotechnology. Transfection efficiency was determined by co-transfection of a Renilla luciferase reporter (pRL-TK; Promega, Madison, WI, USA), pRL-TK Vector $(0.5 \mu \mathrm{g} /$ well). Luciferase activities were measured using a Dual-Luciferase Reporter Assay System (Promega), according to the manufacturer's instructions. Luciferase assays were performed as described previously. ${ }^{37}$ Each treatment was performed in triplicate. Results from three independent experiments were combined.

Statistical analysis. Data were presented as mean \pm s.d., and results were analyzed using SPSS16.0 software. The significance of difference was determined by one-way ANOVA with the post-hoc Dunnett's test. Values of $P<0.05$ were considered to be statistically significant. 


\section{Conflict of Interest}

The authors declare no conflict of interest.

Acknowledgements. This study was supported by the National Natural Science Foundation of China $(81270514,31401210,31571455)$, a project funded by the Priority Academic Program Development of Jiangsu Higher Education Institutions, the Youth Natural Science Foundation of Jiangsu Province (BK20140955), 2013 Program for Excellent Scientific and Technological Innovation Team of Jiangsu Higher Education, the Natural Science Research General Program of Jiangsu Higher Education Institutions (14KJB310011), the Open Project Program of National FirstClass Key Discipline for Pharmacy of Nanjing University of Chinese Medicine (KYLX-0974), and Key Project supported by Medical Science and Technology Development Foundation, Nanjing Department of Health (YKK14143), the Open Project Program of Jiangsu Key Laboratory for Pharmacology and Safety Evaluation of Chinese Materia Medica (JKLPSE 201502) and the Project of the Priority Academic Program Development of Jiangsu Higher Education Institutions (PAPD).

\section{Author contributions}

SZ and HJ designed the study. HJ, NL, FZ, LC, QC and CL performed the experiments. HJ, NL and MB analyzed the data. JS and LW contributed to materials and analysis tools. SZ and HJ prepared the manuscript. SZ provided the financial support. HJ made the drawings in Figure 6. All authors reviewed and approved the manuscript.

1. Kisseleva T, Brenner DA. Hepatic stellate cells and the reversal of fibrosis. J Gastroenterol Hepatol 2006; 21(Suppl 3): S84-S87.

2. Kisseleva T, Brenner DA. Role of hepatic stellate cells in fibrogenesis and the reversal of fibrosis. J Gastroenterol Hepatol 2007; 22(Suppl 1): S73-S78.

3. Friedman SL. Mechanisms of hepatic fibrogenesis. Gastroenterology 2008; 134: 1655-1669

4. Friedman SL. Hepatic stellate cells: protean, multifunctional, and enigmatic cells of the liver. Physiol Rev 2008; 88: 125-172.

5. Krizhanovsky V, Yon M, Dickins RA, Hearn S, Simon J, Miething C et al. Senescence of activated stellate cells limits liver fibrosis. Cell 2008; 134: 657-667.

6. Schnabl B, Purbeck CA, Choi YH, Hagedorn $\mathrm{CH}$, Brenner D. Replicative senescence of activated human hepatic stellate cells is accompanied by a pronounced inflammatory but less fibrogenic phenotype. Hepatology 2003; 37: 653-664.

7. Kuilman T, Michaloglou C, Mooi WJ, Peeper DS. The essence of senescence. Genes Dev 2010; 24: 2463-2479.

8. von Figura G, Hartmann D, Song Z, Rudolph KL. Role of telomere dysfunction in aging and its detection by biomarkers. J Mol Med (Berl) 2009; 87: 1165-1171

9. Karlseder J, Smogorzewska A, de Lange T. Senescence induced by altered telomere state, not telomere loss. Science 2002; 295: 2446-2449.

10. Kim WY, Sharpless NE. The regulation of INK4/ARF in cancer and aging. Cell 2006; 127 265-275.

11. Wang $C$, Jurk D, Maddick M, Nelson G, Martin-Ruiz C, von Zglinicki T. DNA damage response and cellular senescence in tissues of aging mice. Aging Cell 2009; 8: 311-323.

12. Tyner SD, Venkatachalam S, Choi J, Jones S, Ghebranious N, Igelmann $\mathrm{H}$ et al. p53 mutant mice that display early ageing-associated phenotypes. Nature 2002; 415: 45-53.

13. Adamovich Y, Adler J, Meltser V, Reuven N, Shaul Y. AMPK couples $p 73$ with $p 53$ in cell fate decision. Cell Death Differ 2014: 21: 1451-1459.

14. Marra F, Efsen E, Romanelli RG, Caligiuri A, Pastacaldi S, Batignani G et al. Ligands of peroxisome proliferator-activated receptor gamma modulate profibrogenic and proinflammatory actions in hepatic stellate cells. Gastroenterology 2000; 119: 466-478.

15. Zheng $\mathrm{S}$, Chen A. Activation of PPARgamma is required for curcumin to induce apoptosis and to inhibit the expression of extracellular matrix genes in hepatic stellate cells in vitro. Biochem J 2004; 384: 149-157.

16. Park JK, Ki MR, Lee HR, Hong IH, Ji AR, Ishigami A et al. Vitamin $C$ deficiency attenuates liver fibrosis by way of up-regulated peroxisome proliferator-activated receptor-gamma expression in senescence marker protein 30 knockout mice. Hepatology 2010; 51 1766-1777.
17. $\mathrm{Xu} J, F u ~ Y$, Chen A. Activation of peroxisome proliferator-activated receptor-gamma contributes to the inhibitory effects of curcumin on rat hepatic stellate cell growth. Am J Physiol Gastrointest Liver Physiol 2003; 285: G20-G30.

18. Zhou Y, Zheng S, Lin J, Zhang QJ, Chen A. The interruption of the PDGF and EGF signaling pathways by curcumin stimulates gene expression of PPARgamma in rat activated hepatic stellate cell in vitro. Lab Invest 2007; 87: 488-498.

19. Fu Y, Zheng S, Lin J, Ryerse J, Chen A. Curcumin protects the rat liver from CCl4-caused injury and fibrogenesis by attenuating oxidative stress and suppressing inflammation. Mo Pharmacol 2008; 73: 399-409.

20. Zhang F, Zhang Z, Chen L, Kong D, Zhang X, Lu C et al. Curcumin attenuates angiogenesis in liver fibrosis and inhibits angiogenic properties of hepatic stellate cells. J Cell Mol Med 2014; 18: 1392-1406.

21. Zhang Z, Guo Y, Zhang S, Zhang Y, Wang Y, Ni W et al. Curcumin modulates cannabinoid receptors in liver fibrosis in vivo and inhibits extracellular matrix expression in hepatic stellate cells by suppressing cannabinoid receptor type-1 in vitro. Eur J Pharmacol 2013; 721 133-140.

22. Narita M, Krizhanovsky V, Nunez S, Chicas A, Hearn SA, Myers MP et al. A novel role for high-mobility group a proteins in cellular senescence and heterochromatin formation. Cell 2006; 126: 503-514.

23. Storer M, Mas A, Robert-Moreno A, Pecoraro M, Ortells MC, Di Giacomo V et al Senescence is a developmental mechanism that contributes to embryonic growth and patterning. Cell 2013; 155: 1119-1130.

24. d'Adda di Fagagna F. Living on a break: cellular senescence as a DNA-damage response. Nat Rev Cancer 2008; 8: 512-522.

25. Li T, Kon N, Jiang L, Tan M, Ludwig T, Zhao Y et al. Tumor suppression in the absence of p53-mediated cell-cycle arrest, apoptosis, and senescence. Cell 2012; 149: 1269-1283.

26. Hayflick L. The limited in vitro lifetime of human diploid cell strains. Exp Cell Res 1965; 37 614-636.

27. Schrader J, Fallowfield J, Iredale JP. Senescence of activated stellate cells: not just early retirement. Hepatology 2009; 49: 1045-1047.

28. Sasaki M, Nakanuma Y. Cellular senescence in biliary pathology. Special emphasis on expression of a polycomb group protein EZH2 and a senescent marker p16INK4a in bile ductular tumors and lesions. Histol Histopathol 2015; 30: 267-275.

29. Serrano M. Cancer: a lower bar for senescence. Nature 2010; 464: 363-364.

30. Bitto A, Crowe EP, Lerner C, Torres C, Sell C. The senescence arrest program and the cell cycle. Methods Mol Biol 2014; 1170: 145-154

31. Foster DA, Yellen $P, X u L$, Saqcena M. Regulation of $G 1$ cell cycle progression: distinguishing the restriction point from a nutrient-sensing cell growth checkpoint(s). Genes Cancer 2010; 1: 1124-1131.

32. Jacobs JJ. Senescence: back to telomeres. Nat Rev Mol Cell Biol 2013; 14: 196

33. Vigneron A, Vousden KH. p53, ROS and senescence in the control of aging. Aging (Albany NY) 2010; 2: 471-474.

34. Kong $\mathrm{X}$, Feng $\mathrm{D}$, Wang $\mathrm{H}$, Hong F, Bertola A, Wang FS et al. Interleukin-22 induces hepatic stellate cell senescence and restricts liver fibrosis in mice. Hepatology 2012; 56: 1150-1159.

35. Zhang $\mathrm{F}$, Ni C, Kong D, Zhang X, Zhu X, Chen $L$ et al. Ligustrazine attenuates oxidative stress-induced activation of hepatic stellate cells by interrupting platelet-derived growth factor-beta receptor-mediated ERK and p38 pathways. Toxicol Appl Pharmacol 2012; 265 $51-60$

36. Schmittgen TD, Zakrajsek BA, Mills AG, Gorn V, Singer MJ, Reed MW. Quantitative reverse transcription-polymerase chain reaction to study mRNA decay: comparison of endpoint and real-time methods. Anal Biochem 2000; 285: 194-204.

37. Singh V, Biswas RK, Singh BN. Double recombinant Mycobacterium bovis BCG strain for screening of primary and rationale-based antimycobacterial compounds. Antimicrob Agents Chemother 2014; 58: 1389-1396.

Cell Death and Disease is an open-access journal published by Nature Publishing Group. This work is licensed under a Creative Commons Attribution 4.0 International License. The images or other third party material in this article are included in the article's Creative Commons license, unless indicated otherwise in the credit line; if the material is not included under the Creative Commons license, users will need to obtain permission from the license holder to reproduce the material. To view a copy of this license, visit http://creativecommons.org/licenses/by/4.0/ 